\title{
SEMBLANZA
}

\section{Ciencia y tecnología en un mundo más humano: semblanza de los Centros de Formación Humanística del Tecnológico de Costa Rica}

\author{
MSc. Larissa Castillo Rodríguez ${ }^{1}$, Instituto Tecnológico de Costa Rica, \\ Costa Rica y MSc. Elizabeth Corrales Navarro², Instituto Tecnológico de \\ Costa Rica, Costa Rica \\ Recibido: $\quad 27$ de junio, 2018. \\ Aceptado: $\quad 4$ de setiembre, 2018.
}

\section{INTRODUCCIÓN}

El humanismo y la humanística son términos usados indistintamente por muchos estudiosos para referirse a cuestiones de orden antropocéntrico. Los orígenes de este movimiento intelectual se remontan a la época del Renacimiento y tienen como fin adjudicar los grandes descubrimientos científicos a todo el quehacer humano. En este sentido, se dejó atrás el pensamiento de un Dios como hacedor de todas las cosas y se incorporó la idea de protagonizar la labor del ser humano en los avances que iría experimentando la humanidad, en el devenir histórico. La preocupación constante de este movimiento estuvo vinculada con la búsqueda de la libertad, el enriquecimiento del espíritu, mediante el cultivo de las artes, la filosofía y la historia.

Entre los principales representantes de este movimiento estuvieron: Leonardo da Vinci (1452-1519), Francesco Petrarca (1304-1375), Giovanni Pico della Mirandola (1463-1494) y Dante Alighieri (1265-1321). Todos ellos se "dedicaron a reflexionar y escribir sobre la importancia de la libertad de pensamiento para la comprensión y tolerancia entre los seres humanos" (Prada, 2012, p. 72).

Ahora bien, el desarrollo de la humanidad ha propiciado que el humanismo o la humanística, se encuentren en constante evolución. De ahí que el humanismo moderno sea "pensamiento, reflexión, movimiento regenerador y acción política, caracterizado por su capacidad dialéctica, de revitalización constante y mímesis" (Prada, 2012, p. 73). Actualmen-

1 Larissa Castillo Rodríguez es Filóloga y Máster en Historia de Centroamérica, por la Universidad de Costa Rica. Labora como profesora de la Escuela de Ciencias del Lenguaje del Instituto Tecnológico de Costa Rica. Contacto: lacastillo@itcr.ac.cr.

2 Elizabeth Corrales Navarro. Es licenciada en Filología y en Docencia, así como Máster en Ciencias Cognoscitivas, por la Universidad de Costa Rica. Se desempeña como docente de la Escuela de Ciencias del Lenguaje del Instituto Tecnológico de Costa Rica. Contacto: ecorrales@itcr.ac.cr.
Larissa Castillo Rodríguez y Elizabeth Corrales Navarro. Ciencia y tecnología en un mundo más humano: semblanza de los Centros de Formación Humanística del Instituto Tecnológico de Costa Rica. Revista Comunicación. Año 39, volumen 27, número 2, julio-diciembre, 2018. Instituto Tecnológico de Costa Rica. ISSN: 0379-3974 / e-ISSN1659-3820. 
te, hablar de humanismo, de formación humanística, de cursos sobre humanidades significa abordar las distintas corrientes del saber, enfocándose en que la prioridad es el ser humano, sin distinción alguna. Se trata de comprender que la humanística del siglo XXI formará personas libres y autónomas, capaces de crear, reflexionar, decidir, polemizar, o bien, cuestionarse por su existencia.

Es importante indicar, además, que las universidades actualmente cuentan con la gran tarea de formar profesionales integrales, enfocados en entender no solo la dimensión de los avances científico-tecnológicos, sino la necesidad de vincularlos con enfoques humanistas donde medie un balance entre lo racional de la ciencia con lo espiritual y sublime de las humanidades.

Por su parte, el Instituto Tecnológico de Costa Rica (ITCR), universidad destacada en formar profesionales en diferentes ingenierías y Administración de Empresas, cuenta con el programa de Centros de Formación Humanística (CFH), cuyo propósito es "fortalecer en el estudiante una visión global respecto de la problemática actual del desarrollo humano, científico y tecnológico desde una perspectiva humanista, en concordancia con los fines y principios del Estatuto Orgánico" (Reglamento de CFH, artículo 1, 2008, p. 1) .

En virtud de lo anterior, resulta pertinente indicar que este programa concentra su enseñanza en la formación integral de sus estudiantes, mediante cursos con temáticas humanistas, ejercicios académicos que propician debates sobre temas nacionales, internacionales e, incluso, reflexiones sobre la cultura en general. La formación humanística -en este sentido- responde a un programa con el deber de brindarle al estudiante un espacio para pensar en el acontecer mundial y debatir sobre la actualidad política, económica, social y cultural.

El objetivo de esta semblanza obedece al interés de sus autoras por visibilizar la importancia de contar con un programa de $\mathrm{CFH}$ dentro de una universidad de corte científico-tecnológico. Asimismo, el compromiso de ambas por reseñar de qué tratan los $\mathrm{CFH}$, programa que estuvo bajo su responsabilidad en el periodo 2014-2018.

\section{LOS CENTROS DE FORMACIÓN HUMANÍSTICA (CFH): SU GÉNESIS}

Los CFH nacieron en el seno del Primer Congreso Institucional del ITCR, en 1992, de la ponencia del Dr. Arturo Jofré, entonces rector del TEC. Su trabajo titulado "Propuesta sobre la Formación Humana y Social del Profesional del ITCR" planteó la formación humanística como una necesidad de educación integral para la comunidad estudiantil de la institución, y pretendía abrir la posibilidad de incursionar en temas que no se encontraban estrechamente vinculados con la malla curricular de las carreras en ese entonces, pero sí debían formar parte de las mesas de discusión en un ambiente universitario.

Como detalle particular para la aprobación de los $\mathrm{CFH}$, el programa debía contar con un Comité Académico, representado por miembros de los departamento de Cultura y Deporte, Ciencias Sociales y Comunicación (Jofré, 1992, p. 4). Este comité se encargaría de organizar los CFH y presentar los contenidos o temáticas por desarrollar semestralmente al Consejo de Docencia para su respectivo aval. En esencia, esta fue la idea sostenida para iniciar el programa de CFH. La propuesta se avaló y más adelante se presentó a las diferentes instancias para su ratificación: el Consejo Institucional (Acta 172293) y la Asamblea Institucional Representativa (Acta 027-93).

De acuerdo con Jofré, la particularidad del programa radicó en la versatilidad de los cursos y la flexibilización de poder escoger las temáticas. Se trató de un programa distinto a lo tradicionalmente desarrollado en la institución.

El Acta 1722 del Consejo Institucional consigna la información externada por el rector Jofré al defender la propuesta de los CFH:

[...] son temas que curricularmente no se pueden incluir de manera estandarizada [en el plan de estudios como materias semestrales], sino que son cursos abiertos, que incluso funcionarios interesados puedan asistir. Entonces estos centros dan, además, al estudiante, la posibilidad de elegir temas se interés. [...] Siempre he pensado que al 
Instituto le falta algo para ser universidad en el sentido más profundo de la palabra, y es que hay poco diálogo sobre problemas nacionales e internacionales. [Por eso], está muy optimista con estos centros (21 de setiembre de 1993, pp. 24-25).

Los primeros CFH fueron impartidos en 1994, cuando se acordó su carácter obligatorio como requisito de graduación: "Todo estudiante que ingrese a partir de 1994 deberá aprobar tres Centros de Formación Humanística a lo largo de su carrera. Cada Centro durará 5 semanas, tendrá una asignación de 2 horas semanales" (Acta 1932, Consejo Institucional, 17 de abril de 1997, p. 32).

Durante 1995, se desarrollaron cursos de temáticas variadas y se generaron acciones de intercambio de experiencias e internacionalización de los $\mathrm{CFH}^{3}$. En ese año hubo buena aceptación de estos cursos por parte de los directores de departamentos, los consejos de Escuelas y la comunidad institucional en general. La comisión a cargo de los centros estuvo conformada por los académicos Annie Badilla, Brauny Bogantes y Mario Alfaro, los tres profesores de las Escuelas de Ciencias del Lenguaje, Cultura y Deporte y Ciencias Sociales, respectivamente. Ellos tuvieron la gran tarea de dirigir el programa, administrarlo y mejorar la oferta académica semestre a semestre. Entre los CFH impartidos en ese tiempo se destacaron:

$\checkmark$ "Religiones orientales".

$\checkmark$ "El tecnólogo ante el tercer milenio"4.

$\checkmark$ "Desarrollo sostenible en Costa Rica".

$\checkmark$ "Humanismo y poesía en Latinoamérica".

$\checkmark$ "El desarrollo de la ciencia en Costa Rica".

$\checkmark$ "La revolución científica y tecnológica de los siglos XVI y XVII".

$3 \quad$ Al respecto, léase la misiva enviada por Mario Alfaro al entonces rector Alejandro Cruz, el 7 de abril de 1995. En ella, el señor Alfaro expone una serie de notas generales sobre los CFH para que el Rector pueda compartirlas en la Universidad de Murcia y establecer alianzas estratégicas, vinculadas con la formación humana y social, en esa casa de enseñanza.

4 Aprobado en la sesión 05-95 de la Comisión Central de CFH.
De acuerdo con los datos de archivo, los anteriores CFH fueron avalados por la Vicerrectoría de Docencia, sesión 09-95.

La oferta de 1996 se aprobó en la sesión 09 de 1995 por el Consejo de Vicerrectoría de Docencia. Los CFH que se impartieron fueron los siguientes:

$\checkmark$ "Medio ambiente y actitudes: su efecto en el desarrollo de la persona con discapacidad".

$\checkmark$ "Relaciones sociales y procesos tecnológicos".

$\checkmark$ "Costa Rica y las relaciones internacionales".

$\checkmark$ "El pensamiento político de Simón Bolívar".

$\checkmark$ "Autoestima y proyecto de vida".

$\checkmark$ "Religiones orientales II".

Todos los centros fueron desarrollados por estudiosos y expertos en la materia: colaboradores que creyeron en el programa y se conformaron como los primeros instructores de los CFH. En estos dos años de iniciación del programa, los CFH fueron bien recibidos. La gama de cursos abrió la posibilidad de invitar a académicos de otras universidades y proyectar el programa a nivel nacional, además de discutir temáticas de orden humanista y social, complementarias a su formación tecnológica y científica, particular del ITCR. Entre los participantes estuvieron el Dr. Francisco Escobar, el literato Jorge Arturo Venegas Castaing y el sociólogo Dr. Jorge Luis Vega Carballo.

A partir de 1996 el programa de $\mathrm{CFH}$ se ha desarrollado ininterrumpidamente, con carácter de obligatoriedad y como requisito de graduación, tal cual fue aprobado en 1994. No obstante, en 1996 el Consejo de Docencia y el Consejo Institucional recibieron una propuesta particular de eliminar la obligatoriedad de los CFH de la malla curricular de las carreras del TEC, aspecto del cual se tratará en el siguiente apartado.

\section{LA PROPUESTA DE 1996: "ELIMINACIÓN DE LOS CENTROS DE FORMACIÓN HUMANÍSTICA"}

En 1996, los ingenieros Carlos Badilla del área de electrónica y Warner Chaves del área de Física, pre- 
sentaron una propuesta ${ }^{5}$ ante el Consejo de Docencia, cuyo fin era la eliminación del carácter obligatorio de estos cursos como requisito de graduación. La propuesta pretendía que a partir del segundo semestre de ese año se derogara esa condición que tenían los centros: ser un requisito de graduación (Badilla Corrales y Chaves Vargas, 20 de junio de 1996, p. 5B).

Si bien el documento señalaba la necesidad de una readecuación de la enseñanza de la formación humanística: "atinente a los requerimientos y objetivos de los profesionales del TEC (...) integrada y (...) complementaria a la formación en el área de especialidad" (Badilla Corrales y Chaves Vargas, 20 de junio de 1996, p. 2B), no esclarece en ninguna parte cómo subsanar esos vacíos, más que con el mecanismo de evaluación del programa, cuya espera llevaba más de dos años. Por un lado se titula "Eliminación de los CFH" y, por otro, apunta a solo suprimir la obligatoriedad de los cursos, a partir de una serie de razones que refuerzan más bien la necesidad de sostener estos cursos como oportunos y obligatorios, dentro de la malla curricular del estudiante. $\mathrm{Al}$ respecto, la propuesta plantea:

Los centros de formación humanística deben tener mecanismo de evaluación y grados de experiencia correspondientes al nivel universitario, con el fin de que tengan el efecto transformador esperado, sean realmente valorados por el estudiante y cuenten con reconocimiento curricular dentro del sistema universitario estatal" (Badilla Corrales y Chaves Vargas, 20 de junio de 1996, p. 2B).

Es así como el Consejo de Docencia recibió el documento, el 24 de junio de 1996. Valga resaltar que los mismos proponentes resaltaron la importancia de la formación humana y social del TEC, base "fundamental para la consolidación y el progreso de una sociedad democrática" (Acta 08, 1996, p. 5). Consideraron -además- la necesidad de adecuar el nivel de estos cursos pues, así como se encontraban diseñados el estudiante era un receptor y

$5 \quad$ Propuesta que data del 20 de junio de 1996. Fue analizada en el Consejo de Docencia, sesión núm. 8 del 24 de junio del mismo año y es conocida por el Consejo Institucional el 22 de agosto de 1996 (Acta 1932, del 17 de abril de 1997). su aporte no iba más allá que la asistencia al centro de formación.

La propuesta se avaló en esa sesión. El mismo Consejo Institucional, en el acta núm. 1932, del 17 de abril de 1997, revisó el tema de la formación humana y social en el TEC, y acordó evaluar el programa contemplando los siguientes aspectos:

- Su pertinencia.

- El sistema de evaluación empleado.

- El cumplimiento de los objetivos alcanzados.

- Los recursos económicos y financieros asignados.

- El procedimiento administrativo empleado para la realización de los $\mathrm{CFH}$.

- La ubicación de los centros dentro de los planes de estudio de las carreras del ITCR.

- La cantidad de centros que la institución debe impartir por año para cumplir con los objetivos trazados.

No se tiene al alcance más información de esos años para determinar si se realizó la evaluación al programa. Se intentó conseguir los resultados de esa evaluación. No obstante, fue imposible encontrarlos. Lo que sí se constata es la permanencia del programa de centros de formación humanística, desde 1996 hasta la fecha, cuyo mecanismo no ha variado desde su creación: son cursos cortos, se aprueban por asistencia y responden a diez horas de desarrollo del tema.

\section{LOS CENTROS DE FORMACIÓN HUMANÍSTICA EN LA ACTUALIDAD}

Desde el año 2000, el programa de CFH está liderado por la Escuela de Ciencias del Lenguaje, instancia encargada de velar por la administración y oferta académica del programa en los campus tecnológicos de Cartago, San José, Alajuela y Limón. El programa cuenta con seis matrículas al año y una en el periodo de Verano (diciembre de cada año). Ciencias del Lenguaje organiza y propone una oferta de cursos enfocados en diversos campos del sa- 
ber humano y social. Las plenarias corresponden a un total de 10 horas, como se indicó antes. En ellas se discuten los temas propuestos con la comunidad estudiantil y docente ${ }^{6}$.

Centros de Formación se nutre del apoyo y colaboración de distintas escuelas y departamentos del TEC interesados: desde Ciencias Sociales, Cultura y Deporte, hasta Computación, Electrónica y Comunicación, entre otras, así como de la participación de profesores pensionados, quienes se mantienen activos en el ejercicio de la docencia mediante estos cursos.

Además, de acuerdo con lo estipulado en el reglamento y consignado en el acta del Consejo Institucional, "los Centros podrán ser impartidos por cualquier departamento docente de la Institución, una vez que se aprobara la temática por la Comisión Organizadora de los Centros" (Acta 1932, Consejo Institucional, 17 de abril de 1997, p. 32). Esta comisión (que en 1997 se llamaba "Comisión Organizadora de los Centros") actualmente corresponde a una comisión central, encargada de supervisar el buen funcionamiento del programa y la pertinencia de las nuevas propuestas. El equipo de trabajo está integrado por los directores de las Escuelas de Ciencias del Lenguaje, Ciencias Sociales, Cultura y Deporte, así como por los coordinadores de las sedes y un representante estudiantil nombrado por el Consejo Ejecutivo de la FEITEC (Reglamento de $\mathrm{CFH}$, artículo 4). Se trata de una entidad que ha servido de soporte al trabajo de los diferentes coordinadores de cada sede. El campus tecnológico de San Carlos cuenta con su autonomía administrativa y académica, aunque también, forma parte de esta comisión.

La formación humanística en el ITCR ha estado al servicio de toda la comunidad estudiantil y docente. Los cursos impartidos, así como las temáticas propuestas por académicos de diferentes disciplinas han enriquecido al programa y han permitido que a lo largo de estos años los estudiantes de las carrera científico-tecnológicas puedan contar con acercamientos a temas propios de su realidad nacional,

$6 \quad$ Importante es hacer notar que la comunidad académica puede participar de estas sesiones con los estudiantes, si tienen el interés de hacerlo. sensibles con su contexto histórico y cuya información cultural y social los conduzca a cuestionar críticamente su entorno, desde diferentes perspectivas epistemológicas.

Actualmente, durante el periodo de gestión 20142018, el programa ha ofertado una gama de cursos de distintas áreas: literatura, psicología, derecho, filosofía, comunicación y sociología. Entre los cursos regulares destacan:

- Hacia una lectura crítica de los medios. ¿Cómo aprender a enfrentarse mejor a lo que los medios dicen?

- Sexualidad y prevención, dimensión social de la intimidad: VIH-SIDA.

- Literatura y erotismo: un análisis de Cuentos sucios y otros relatos.

- Literatura y cultura: dialéctica a partir de textos latinoamericanos.

- Desconcierto de amenaza nuclear en la Península de Corea.

- Tres naturalistas costarricenses: Alfaro, Torres y Skutch.

- Estado o mercado: el origen de la discusión ideológica.

- El principio constitucional del debido proceso.

- Filosofía y feminismos desde la cotidianidad.

- Factores psicosociales de la salud mental.

- Movimientos estudiantiles universitarios.

- Sexualidad, pareja y teoría psicosexual.

- Internet, ventana de Posmodernidad.

- Derechos Humanos y discapacidad.

- Lenguaje y producción audiovisual.

- Desarrollo del arte en Costa Rica.

- Autoestima y proyecto de vida.

- Hablemos de discapacidad.

- Ciencia y filosofía griega.

- Cultura de la alteridad.

- Cine y Literatura.

Ahora bien, como parte de este proceso de construcción de la semblanza, las autoras buscaron conocer el criterio de los coordinadores, quienes estuvieron a cargo -en diferentes momentos- desde el inicio 
del programa. Su objetivo fue recopilar información sobre las experiencias vividas como encargados de los centros, así como también conocer detalles relacionados con la labor administrativa y académica, y -muy importante- la concepción humanística de cada uno, aspecto que interesa destacar en este escrito.

Colaboraron, muy amablemente, Mario Alfaro Campos, Annie Badilla Calderón (filóloga), Brauny Bogantes Arias, José Jacinto Brenes Molina, Enrique Hernández Camacho y María Gabriela Amador Solano. Todos ellos estuvieron a cargo del programa en periodos distintos.

Así por ejemplo, Alfaro Campos apuntó a sostener la idea de la formación humana y social como "una integridad, necesaria para el desarrollo profesional de cualquier joven estudiante" (Comunicación personal, 27 de mayo de 2015). Annie Badilla, por su parte, indicó que se trataba de "un conocimiento de la realidad del ser humano, su formación y distinción de otras especies" (Comunicación personal, 6 de junio de 2017). Para Brauny Bogantes, "los centros son formación para vida y no solo para un momento particular" (Comunicación personal, 29 de julio de 2015). Por su parte, José Jacinto Brenes sostuvo siempre la importancia de "sensibilizar al ser humano desde los CFH. Este programa, en sus palabras, ha permitido la posibilidad de apreciar las Bellas Artes, las corrientes filosóficas y artísticas, además de desarrollar esa sensibilidad manifiesta en la solidaridad en pro de las causas sociales" (Comunicación personal, 28 de julio de 2015). Enrique Hernández, con una opinión más aguda, vio la formación humanística como un agregado dentro de una universidad tecnológica. Indicó la necesidad de superar esa concepción y colocar la formación humanística en un plano protagónico, en el contexto del siglo XXI (comunicación personal, 21 de julio de 2015). Finalmente, María Gabriela Amador le reconoce a la formación humana y social la oportunidad que tiene el estudiante de conocer otras disciplinas diferentes a su formación científica. Se trata de tener acceso al conocimiento que prioriza el desarrollo del espíritu del ser humano (comunicación personal, 24 de junio de 2015).
Las gestiones académicas y administrativas de todos ellos estuvieron marcadas por características particulares. En general, todos apuntaron a señalar la grata experiencia de haber dirigido un programa con una oferta de cursos tan variada, con la posibilidad de estrechar relaciones académicas con otras escuelas del ITCR. Asimismo, destacaron la lucha por conseguir presupuesto, no solo para remunerar a los docentes, sino para invitar a académicos e intelectuales externos al ITCR, de disciplinas vinculadas con la formación humana y social. En fin, un programa cuyo aprendizaje fue vasto y enriquecedor.

También apostaron a reconocerle a las Humanidades su visión integradora y sensibilizadora de los aspectos cotidianos, ya que se sabía que la formación humanística serviría para despertar la creatividad e incentivar el pensamiento crítico.

Finalmente, los mayores retos actuales e históricos se han discutido de una forma crítica y humana. Por lo tanto, debe estar claro que las universidades tienen la gran responsabilidad de formar profesionales capaces de leer e interpretar su propio contexto; esto es, poniendo en una balanza las ciencias y las humanidades, pensando siempre como prioridad su condición de ser humano.

\section{EL XX ANIVERSARIO DEL PROGRAMA}

Como una forma de visibilizar el programa y rendir homenaje a la importancia de las humanidades en el TEC, se celebró durante el 2016 el XX aniversario con el lema: "Ciencia y tecnología en un mundo más humano", con una importante participación de la comunidad estudiantil y docente, se prepararon actividades culturales y académicas.

Se abrió la celebración con la exposición fotográfica "Somos como somos", a cargo de la periodista Marcia Silva. El trabajo de Silva se reconoce por conjugar los términos cuerpo, libertad, tecnología y humanismo en cada una de sus tomas fotográficas. Atinada temática este para recordar el lema asignado al programa. Las siguientes imágenes corresponden a un extracto de esta exposición y representan la conjunción entre humanidad y tecnología. A esta 


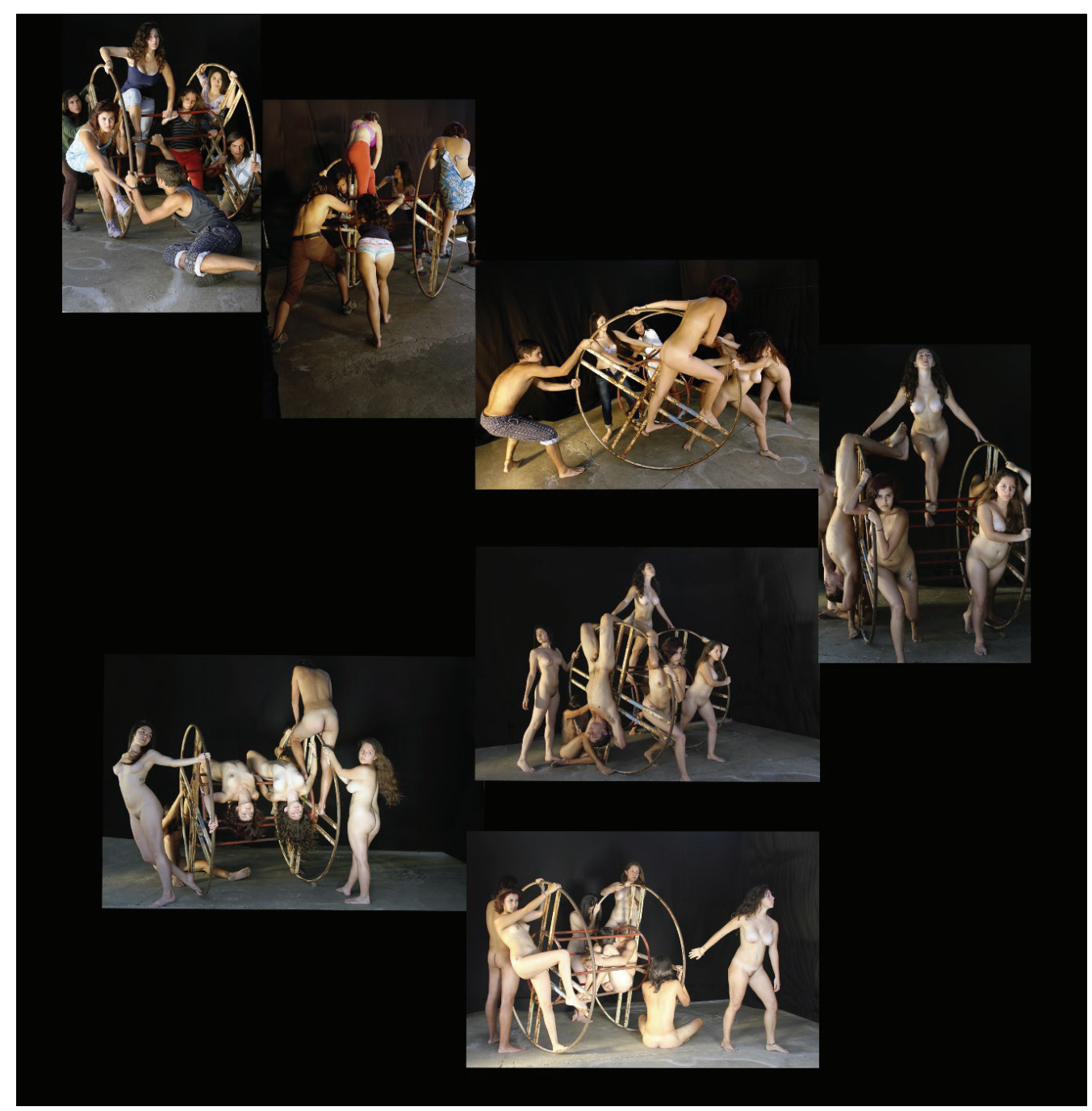

"Alegoría de la juventud" (2016). Serie: Rueda de la vida. Tamaño: 44×44

Fuente: Cortesía de Marcia Silva Pereira

secuencia Silva la denominó "Alegoría de la juventud".

A la luz de esta exposición fotográfica, se organizó el ciclo de cine: "Cuerpo y Libertad", en cuatro sesiones que concluyeron con una mesa redonda a cargo de Marcia Silva (fotógrafa-periodista), Ana Rosa Ruiz (economista y coordinadora de la oficina de Equidad de Género del ITCR), Alicia Coto (artista plástica) y Karina Avellán (cineasta). Ellas comentaron las películas: Petals, El lado oscuro del corazón, The pillow book y Naked world.

También se coordinó el diseño de un mural representativo de la formación humana y social en el
ITCR. Este fue diseñado por el artista plástico Nelson Díaz, de la Escuela de Cultura y Deporte. Un trabajo cuyo énfasis fue decirle a toda la comunidad la relevancia de contar con las humanidades en los espacios de la educación superior. El mensaje divulgado en las tarjetas - con el diseño del mural impreso- fue escrito por Larissa Castillo, coordinadora del periodo 2014-2018, y entregado al personal docente y administrativo del ITCR. Tuvo una clara señalización de esa visión integradora que deben mantener los $\mathrm{CFH}$ : 


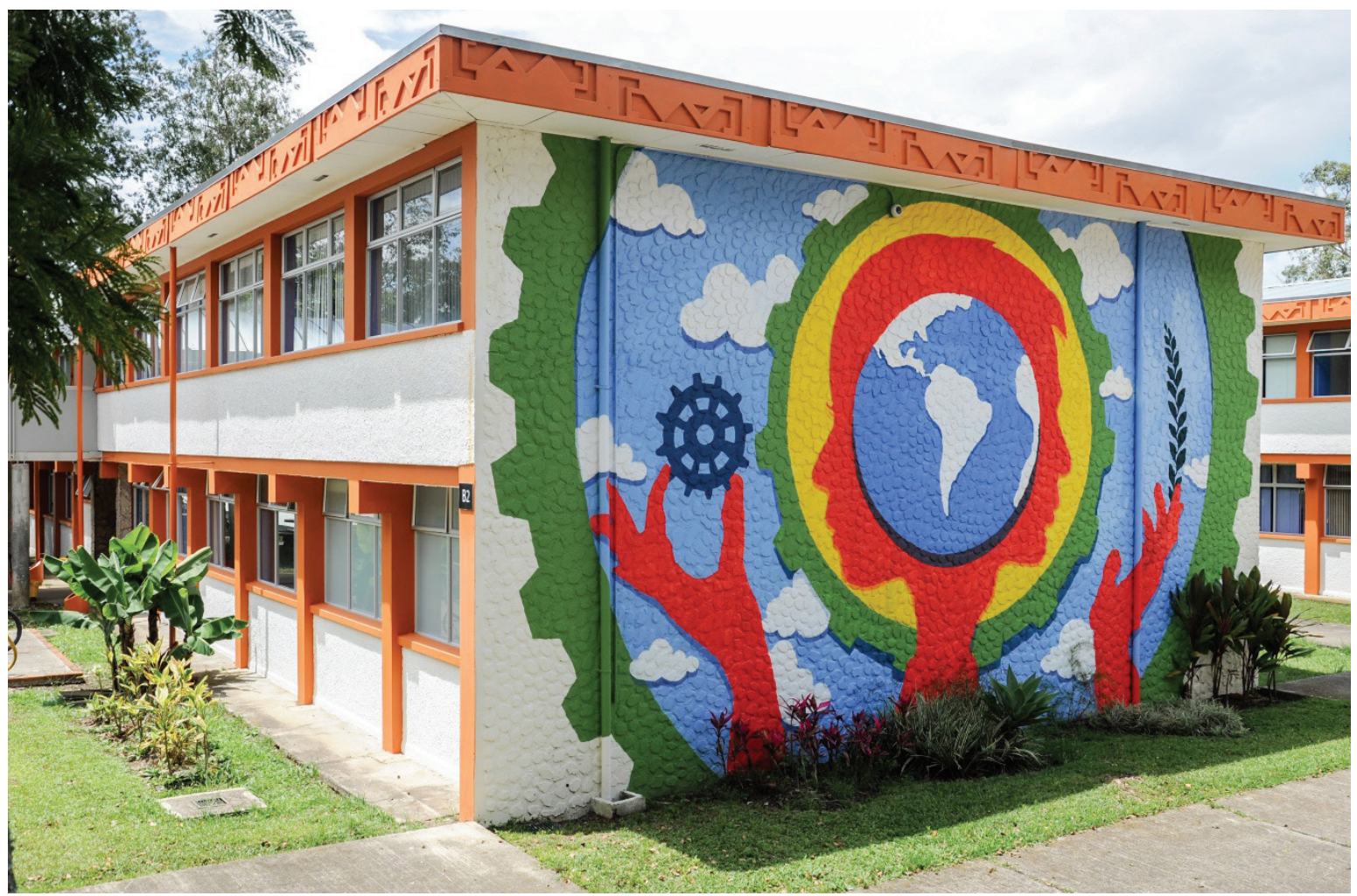

Fuente: Andrés Zúñiga, asistente en fotografía, departamento de Comunicación y Mercadeo del ITCR

Conmemorar estos XX años significa rendirle honor al ser humano y a su vínculo con la ciencia y la tecnología. El proyecto del mural pretende ser un referente no solo de la formación humanística en el TEC, sino de la importancia y el reto que tienen las humanidades de colocar en el centro de su quehacer al SER HUMANO, sin distinción de género, raza, religión o ideología. Este homenaje implica visibilizar que el futuro de los CFH está asegurado, porque continúa vigente la necesidad de la literatura, la historia, la filosofía, el arte, la psicología, la antropología, la sociología, el derecho y muchas disciplinas interesadas en colocar al ser humano como centro de atención en su quehacer profesional y académico (Castillo, 2016).

También hubo otras actividades con destacados pensadores nacionales, por ejemplo, el Dr. Rolando Araya Monge, quien se dirigió a la comunidad nacional en una conferencia programada en el campus tecnológico de San José:

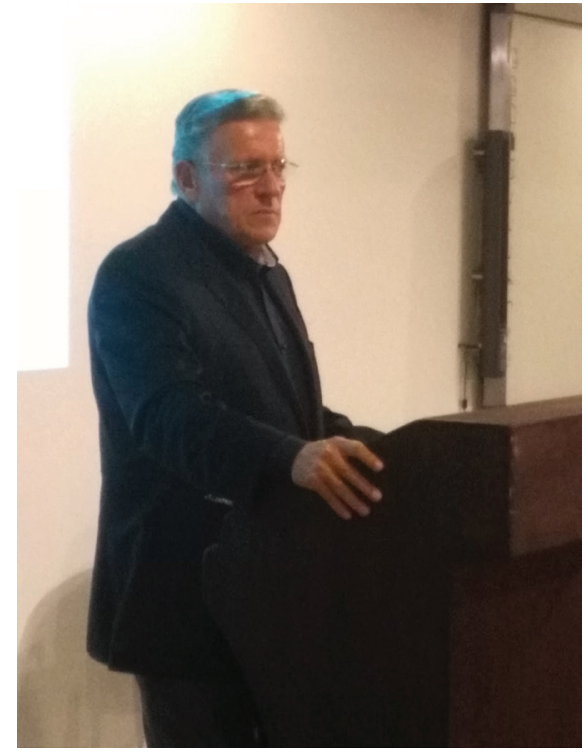

Rolando Araya Monge, en conferencia efectuada el 21 de octubre de 2016, titulada "Un nuevo paradigma cuántico". Campus Tecnológico de San José

Se concluyó la conmemoración del aniversario con la organización de un concurso de ensayo, cuyo tema fue precisamente el lema de los CFH. Se hizo 
extensiva la invitación a toda la comunidad estudiantil. No obstante, los cursos regulares de Comunicación Escrita del ITCR fueron el espacio ideal para incentivar la participación en el concurso. Estos sirvieron de soporte a los estudiantes y los profesores encargados dieron acompañamiento a los interesados en participar. El jurado estuvo integrado por un equipo interdisciplinario: Martha Calderón (abogada de la Escuela de Ciencias Sociales), Juan Mauricio Garro (filósofo de la Escuela de Ciencias Sociales), Guillermo Coronado (filósofo, profesor de $\mathrm{CFH}$ ) y Gerardo Lacy (físico de la Escuela de Física). Asimismo, hubo conferencias en las sedes de San José y Alajuela para conmemorar estos 20 años. Fue un 2016 que rememoró la importancia de los CFH en el ITCR y quedará en la memoria de quienes asistieron y participaron en las actividades programadas.

\section{CONCLUSIÓN}

Tres son las razones más fuertes que mueven a pensar en la gran importancia de una formación humana y social dentro del ITCR:

a- Debe existir un balance entre los estudios en Ingeniería y las Humanidades. Se necesitan profesionales identificados con la realidad nacional, capaces de resolver los problemas de manera integral. El balance entre ciencia-tecnología y humanidades permite construir proyectos y solucionar problemas poniendo como prioridad la cuestión humana y social.

b- La formación humanista amplía el interés y la educación. El mundo requiere científicos-tecnológicos, "pero también de personas que entiendan los por qué y cómo del comportamiento humano" (Olejarz, 2017). Es primordial que la cultura científica se apoye en la cultura humanística y viceversa. El ITCR debe reconocer que la mayor riqueza de un país son las personas y por ello considerar fundamental generar capacidades y oportunidades para ellas.

c- La legislación del ITCR contiene como primer eje transversal: El ser humano como principio y fin de la acción institucional; es decir, la universidad está comprometida con los intereses, problemas y cuestionamientos relacionados con el ser humano. Para lograr el perfil del nuevo ciudadano, con las exigencias del siglo XXI: un ser humano con capacidades intelectuales idóneas, así como con disposición para trabajar en equipo, que conviva con los demás colegas y aporte sus competencias epistemológicas, la universidad tiene el gran reto de planificar y adecuar sus planes de estudio, de forma tal que se apueste a la formación integral.

La labor de los CFH es fundamental. Por lo tanto, las Humanidades deben estar presentes y unidas a la ciencia y la tecnología. Además, las Humanidades del siglo XXI tienen que abordarse no solo a partir de cursos especializados, sino a través de toda una formación profesional, puntualizando en que los estudios en general son desarrollados por humanos creativos, sensibles, imaginativos, libres, conscientes de su contexto político, económico, social y cultural.

El reto de esta universidad será encontrar la fórmula para equilibrar la calidad de la educación con los grandes avances y nuevos descubrimientos científicos, sin perder de vista que ciencia y tecnología deben estar al servicio del ser humano y no a la inversa.

Tal cual lo expone Prada (2012): "hacer del humanismo una práctica social y política de vida cotidiana, en tiempos de globalización y libre mercado, es el reto al que nos enfrentamos en este nuevo milenio". En ese sentido, los Centros de Formación Humanística podrían servir de plataforma para enseñar que la educación del ser humano y del científico joven se sustenta en una necesidad de comprender y hasta modificar su entorno, eso sí, con un profundo sentido social.

Queda mucho trabajo por hacer: la aprobación de un nuevo reglamento para este programa, la ampliación de las horas que comprende cada curso, una mayor participación de académicos TEC, publicaciones académicas concentradas en el eje de las Humanidades del siglo XXI, así como la realización de proyectos de investigación y extensión, entre otros más. No obstante, las autoras reconocen el valor de los CFH en una universidad tecnológica 
y hacen honor al lema de este programa, consignado en la celebración del XX aniversario: "Ciencia y tecnología en un mundo más humano".

\section{REFERENCIAS BIBLIOGRÁFICAS}

Bonilla Zamora, J. (2013). Las humanidades: hoy y mañana. Revista Chilena de Literatura, (84), 219221. Recuperado de https://revistaliteratura.uchile.cl/index.php/RCL/article/view/28517/39133.

Olejarz, J.M. (2017). Las humanidades son el futuro de la economía digital y la tecnología. Harvard Business Review. Recuperado de: https://www. hbr.es/educaci-n/697/las-humanidades-son-elfuturo-de-la-econom-digital-y-la-tecnolog.

Prada, G. (2012). El humanismo y la educación en tiempos de globalización. Revista Comunicación, 21 (2), 71-74. Disponible en file:///C:/Users/ecorrales/Downloads/1386-Texto\%20del\%20art\%C 3\%ADculo-4507-1-10-20130625.pdf.

Quirós, M.A. (2010). Homo sum...o el humanismo. Káñina, XXXIV (1), 81-98. Disponible en file:///C:/ Users/ecorrales/Downloads/1064-Texto\%20 del\%20art\%C3\%ADculo-1491-1-10-20120813. pdf.

Ramírez, J. (2003). Humanismo sin humanistas. Revista Comunicación, 12 (1 y 2), 178-184. doi: https://doi.org/10.18845/rc.v12i1\%20y\%20 2.1195

Trujillo, J.F. (2009). Formación humanística o formación por competencias: dilemas de la educación en el contexto actual. El Hombre y La Máquina. 32 (9), 8-19. Recuperado de http://www.redalyc. org/articulo.oa?id=47811604002.

\section{FUENTES DE ARCHIVO}

Instituto Tecnológico de Costa Rica. (1993). Acta de la Asamblea Institucional Representativa ITCR. Acta 027-93.

Badilla Corrales, C. y Chaves Vargas, W. (20 de junio de 1996). Propuesta: Eliminación de los Centros de Formación Humanística.
Centros de Formación Humanística, Comisión Central (1995). Acta 05-95.

Comisión Organizadora del I Congreso Institucional. Informe Final.

Consejo Institucional del ITCR (1993). Acta 172293.

Consejo Institucional del ITCR (1997). Acta 193297.

Jofré, A. (1992). Propuesta sobre la formación humana y social del profesional del Instituto Tecnológico de Costa Rica. Ponencia presentada en el I Congreso Institucional.

Reglamento de Centros de Formación Humanística, aprobado el 4 de setiembre de 2008.

Vicerrectoría de Docencia/Consejo de Docencia. (1995). Acta 09-95.

Vicerrectoría de Docencia/Consejo de Docencia. (1996). Acta 08-96. 